\title{
Undersea project delivers data flood
}

\author{
Sea-floor observatory in the Pacific Ocean to provide terabytes of data.
}

\section{VICTORIA, CANADA}

Results are pouring in from an ambitious project that has wired the floor of the northeast Pacific Ocean with an array of cameras, seismometers, chemical sensors and more. The challenge won't be getting good data, but rather handling the vast quantities of it, project scientists reported last week at their first post-launch meeting in Victoria, Canada.

The Can\$145-million (US\$145million) project, called NEPTUNE Canada (North-East Pacific TimeSeries Undersea Networked Experiments), has laid 800 kilometres of cable to transmit power and data, and established five 'nodes' that act like giant, 13-tonne plug-in points for scientific instrumentation, lying up to 2.6 kilometres beneath the waves (see map). The network spans the Juan de Fuca plate, which sits between the Pacific and the North American plates and hosts earthquakes and tsunamis, giant clams and whale pods, along with hydrothermal vents and frozen methane deposits.

NEPTUNE Canada is the leading effort to wire a wide region of ocean floor with multiple sensors, making real-time, interactive data streams freely available to anyone online. It is breaking ground for similar networks elsewhere, including Japan (the Advanced Realtime Earth Monitoring Network in the Area, or ARENA) and Europe (the European Sea Floor Observatory Network, or ESONET). Scientists want to use NEPTUNE Canada to study how different systems interact, answering questions such as whether earthquakes trigger methane release, and how climate change is affecting the ocean.

The project was launched in December 2009 after a decade of work. Three-quarters of its 78 instruments are delivering data at present, and, despite some teething problems, project scientists are delighted by the progress. "I'm flabbergasted," says Mairi Best, associate director of science for the project at the University of Victoria. "Everyone was painfully aware of how many pieces are involved, how many ways it could go wrong."

The original vision for NEPTUNE called for 3,000 kilometres of cable off the coast of
Canada and the United States. But the US contribution has been held up, having only recently received funding as part of the 2009 economic recovery package. US project managers now plan to install 800 kilometres of cable and several nodes that should be up and running by 2014. "It is a shame that the time-lag has split
THE NEPTUNE NETWORK

Instruments are connected by 800 kilometres of cable across the Juan de Fuca tectonic plate, bounded at its northwest edge by the Endeavour ridge.

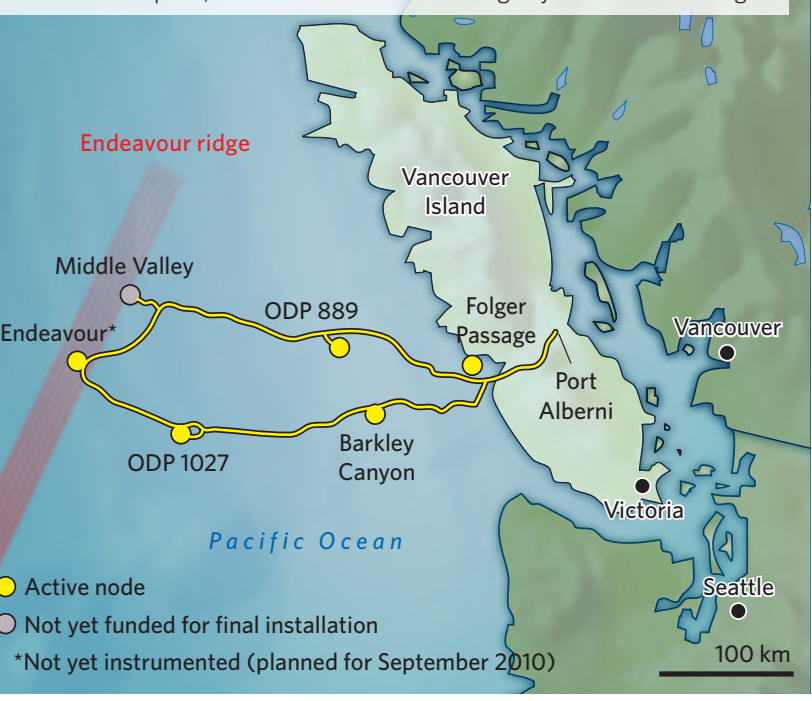

a substantial change for oceanographers, who are used to obtaining isolated bursts of data from week-long cruises, and then spending a year analysing the results. "Half of our staff are in data management," says Best. In terms of data handling, "everyone is outside of their comfort zones", she says.

The fact that the data are freely available online should spur the scientists in charge of each instrument to make the most of the results, says Benoît Pirenne, who heads NEPTUNE's data management and was previously in charge of archiving astronomical data for the European Southern Observatory. "If they don't analyse it, someone else will," he says. Teams are looking for innovative ways of crunching through the data, including getting the public to help watch the vast quantities of video archive and highlight noteworthy events.

Early results from NEPTUNE Canada include seismometer readings from the Chilean earthquake in February, and bottom-pressure sensor results that tracked the small tsunami waves it generated. The project also has a crawler called Wally (named after the robot in

the project," says Brian Bornhold, a marine geologist and NEPTUNE Canada project scientist at the University of Victoria. But the two countries still plan to work closely together. "The Canadian success is absolutely fantastic," says John Delaney, an oceanographer at the University of Washington, Seattle, who helped to dream up the idea for NEPTUNE and is working on the US If they don't analyse it, someone else will."

project. He thinks that such vast ocean monitoring systems will become more common in the future: "This is the first of them; it is by no means the last."

\section{Bit torrent}

NEPTUNE Canada is now sending about 0.1 terabytes ( $10^{12}$ bytes) of data back to shore every day, and should ramp up to about 60 terabytes per year. This may be small scale for, say, particle physicists - the Large Hadron Collider is expected to generate an annual 15 petabytes $\left(10^{15}\right.$ bytes $)$ of data - but it marks the 2008 film $W A L L \cdot E$ ) that is investigating methane beds by remote operation from Germany. The results could help to improve estimates of how much methane, a potent greenhouse gas, is being released from oceans.

To get renewed government funding, the project will have to prove its worth by generating demand, says Martin Taylor, chief executive of the Ocean Networks Canada, the agency managing NEPTUNE Canada. So far, thousands of users in 71 countries have signed up for free access to the data, says Best. The project hopes to raise funds by charging companies to test new oceanographic instruments on the NEPTUNE network, and to sell parts of their data-management system.

The first maintenance expedition, planned for May this year, will show how well the instruments are holding up to the high pressure and salt water. "We're learning a lot," says Pirenne, "which is another way of saying that things are breaking."

Nicola Jones 